\title{
Conference Report
}

\section{Four Windows on Modern Science in Flavor and Fragrance Chemistry at Firmenich Geneva, Switzerland, 5th December 2011}

\section{Christian Starkenmann* and Laurent Wünsche}

${ }^{*}$ Correspondence: Dr. C. Starkenmann, Firmenich SA, Corporate R\&D Division, P.O. Box 239, CH-1211 Geneva 8, Tel.: +4122 780 3477, Fax: +4122 7803334

E-mail: christian.starkenmann@firmenich.com

Abstract: Four young scientists, recently hired by Firmenich, presented lectures at the University of Geneva. The objective was to stimulate young students to choose sciences. The challenges in the discovery, synthesis, or extraction of new molecules were presented, as well as the structure-activity relationships of human odorant receptors.

\section{Keywords: Conference report: Firmenich}

The Société Chimique de Genève organized a conference at the University of Geneva in partnership with Firmenich SA, Geneva, to celebrate the International Year of Chemistry and to stimulate new vocations in chemistry. The Auditorium of Sciences II at the University of Geneva was overfull, as close to 180 people attended this event. The organizing committee was very pleased to see many undergraduate students in attendance. The presentations were given by four young scientists, who started their career at Firmenich between 2006 and 2010.

Dr. Laurent Wïnsche, director of the group of analytical innovation at Firmenich R\&D and vice president of the Société Chimique de Genève, opened the conference by welcoming the audience and presenting a short introduction to the world of perfumery and flavors. The science sessions were chaired by Dr. Christian Starkenmann, principal scientist at Firmenich, and began with a presentation by Dr. Estelle Delort in which she gave a general overview of citrus knowledge at Firmenich, with a focus on the analytical aspects.

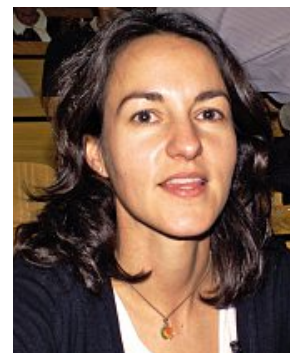

Dr. Estelle Delort
Citrus is an endless source of research work. The citrus family contains more than a hundred different species and new citrus hybrids are being developed by citrus breeders and geneticists. This large diversity of plants results in great molecular diversity. The volatile composition of the peel and juice of common citrus varieties such as orange, lemon, mandarin, grapefruit, lime, and bergamot have been thoroughly investigated by gas chromatography and mass spectrometry (GC/MS), as well as by GC/olfactometry. In general, the volatile components of citrus peel oils and juice extracts consist of dominant amounts of the same terpenes, carbonyls, and sesquiterpenes. The characteristic organoleptic signature of each species is due to a complex, well-balanced mixture of these major components, but also to key molecules such as citral in lemon and lime, nootkatone in grapefruit, methyl N-methyl anthranilate in mandarin, and linalyl acetate in bergamot, to cite only a few. Analytical work done in-house has also showed the importance of some trace compounds in the overall aroma, for example, pyridines in orange oils, new potent aldehydes in fresh lemon peel, and sulfur compounds in grapefruit and in less common citrus such as Poncirus trifoliata L.

The second presentation by Dr. Julien Coulomb focused on the strategies to synthesize organic molecules that have a sandalwood odor. The essential oil of sandalwood (Santalum album L.), from eastern India, is a very valuable material for fine fragrances. The important odorant molecules in the essential oil are (Z)-(-)-( $\beta$ )-santalol (20-25\% of the essential oil), which smells like natural wood and is highly appreciated, and $(Z)-(+)-$ $(\alpha)$-santalol (45-50\% of the oil), which smells like sandalwood but with a less desirable cedar olfactive tonality.

The cost of this essential oil can vary considerably and the overexploitation of the tree has led the industry to search for a synthetic alternative. For this reason, two classes of compounds derived from camphene or campholenic aldehyde, including Dartanol ${ }^{\mathrm{TM}}$, Polysantol ${ }^{\circledR}$, and Firsantol ${ }^{\circledR}$. The alcohol $\mathbf{1}$ (Fig. 1) is substantive, fresh, and very close in its odor profile to natural sandalwood odor. This molecule was recently patented, as Dr. Coulomb described. A new approach

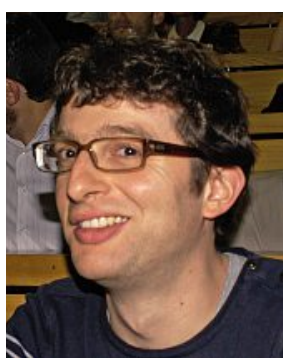

Dr. Julien Coulomb to synthesizing $(Z)-(-)-(\beta)$-santalol could constitute the first industrial synthesis of this very precious compound. The key step in its synthesis is the fragmentation of the enynol $\mathbf{2}$ catalyzed by a copper (I) salt, allowing the formation of $\mathbf{3}$ to add the side chain in exo position (Scheme 1).

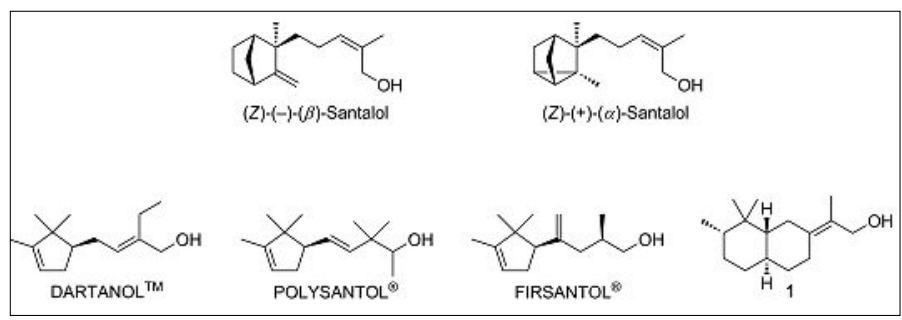

Fig. 1. Structure of sandalwood-smelling compounds.

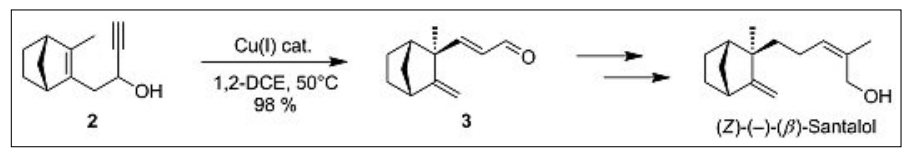

Scheme 1. New synthetic approach to (Z)-(-)-(ß)-santalol.

In the third presentation, Dr. Jonas Schenk discussed the production of natural ingredients for the fragrance and flavor industry. Natural ingredients were traditionally produced through steam distillation or extraction of botanicals. These methods are today still widely used for patchouli oil, mint oil, and vanilla extracts, for example; however, in the future, biotechnology processes will likely be used. Enzymatic catalysis and fermentation processes using microorganisms are already used

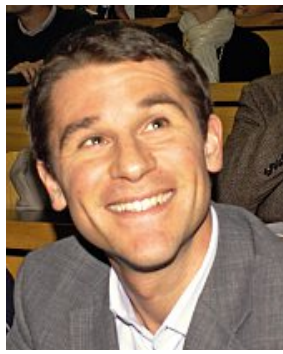

Dr. Jonas Schenk 
to produce natural ingredients. Dr. Schenk highlighted that both the extraction of botanicals and the use of biotechnology required the same efforts to engineer new separation processes. They involve the treatment of the same type of aqueous dilute solutions embedded with complex mixtures of macromolecules, which generate challenging engineering purification designs.

Finally, Dr. Sanja Narancic discussed the molecular aspects of odor perception. Millions of olfactory sensory neurons

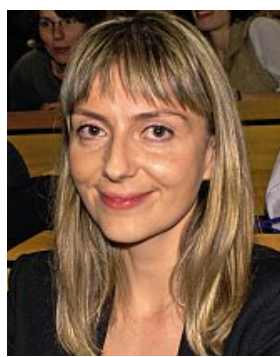

Dr. Sanja Narancic containing more than 400 olfactory receptor proteins work in concert to generate our sense of smell. It is generally accepted that the encoding of odor quality follows a combinatorial receptor scheme, in which different odorous ligands are recognized by distinct subsets of the 400 olfactory receptor proteins (S. Firestein, Nature 2001, 413, 211-218). From the peripheral olfactory code, can olfactively related chemicals be associated, even when their structures appear to be unrelated? Dr. Narancic described several approaches on how to tackle the problem of decoding the olfactory receptor code by correlating conserved elements in the chemical structure of odorous ligands with the perceived quality of their odors.

Professor Jérôme Lacour, president of the Société Chimique de Genève, chaired the animated discussion and question session for the four speakers, which concluded this scientific journey into the fascinating world of flavor and fragrance chemistry.

After the well-deserved acknowledgements to all speakers and to the organization committee, Prof. Lacour invited the audience to stay for refreshments, allowing the participants to continue the discussions and offering them the opportunity to smell some of the compounds that were presented during the talks.

Finally, all participants were also invited to visit the recently inaugurated 'Chimiscope', a spectacular initiative of the chemistry section of the University of Geneva to attract new generations to the exciting world of chemistry. 